Article

\title{
Low Cost, Lightweight Gravity Coring and Improved Epoxy Impregnation Applied to Laminated Maar Sediment in Vietnam
}

\author{
Jan P. Schimmelmann ${ }^{1, *}$, Hướng Nguyễn-Văn ${ }^{2}{ }^{10}$, Dương Nguyễn-Thuỳ 2 (1) and \\ Arndt Schimmelmann ${ }^{3}$ \\ 1 Institute of Geography, University of Bremen, Celsiusstrasse 2, D-28359 Bremen, Germany \\ 2 Faculty of Geology, VNU University of Science (HUS), 334 Nguyen Trai, Thanh Xuan District, \\ Hanoi, Vietnam; huongtectonics@vnu.edu.vn (H.N.-V.); duongnt_minerals@vnu.edu.vn (D.N.-T.) \\ 3 Department of Earth and Atmospheric Sciences, Indiana University, Bloomington, IN 47405-1403, USA; \\ aschimme@indiana.edu \\ * Correspondence: jschimme@gmail.com; Tel.: +49-157-353-520-55
}

Received: 4 April 2018; Accepted: 7 May 2018; Published: 11 May 2018

\begin{abstract}
In response to the need for lightweight and affordable sediment coring and high-resolution structural documentation of unconsolidated sediment, we developed economical and fast methods for (i) recovering short sediment cores with undisturbed topmost sediment, without the need for a firmly anchored coring platform, and (ii) rapid epoxy-impregnation of crayon-shaped subcores in preparation for thin-sectioning, with minimal use of solvents and epoxy resin. The 'Autonomous Gravity Corer' (AGC) can be carried to remote locations and deployed from an inflatable or makeshift raft. Its utility was tested on modern unconsolidated lacustrine sediment from a $\sim 21 \mathrm{~m}$ deep maar lake in Vietnam's Central Highlands near Pleiku. The sedimentary fabric fidelity of the epoxy-impregnation method was demonstrated for finely laminated artificial flume sediment. Our affordable AGC is attractive not only for work in developing countries, but lends itself broadly for coring in remote regions where challenging logistics prevent the use of heavy coring equipment. The improved epoxy-impregnation technique saves effort and costly chemical reagents, while at the same time preserving the texture of the sediment.
\end{abstract}

Keywords: core catcher; epoxy resin; gravity corer; impregnation; limnology; sediment corer; thin section

\section{Introduction}

Fine-grained lacustrine and marine laminated sediments contain valuable high-resolution archives of (paleo)environmental conditions, especially when laminations are annual (i.e., varves [1,2]). The high-resolution structural and compositional information in unconsolidated sediment requires utmost care in sediment coring and preservation of cores. The recovery of modern undisturbed sediment with an intact sediment/water interface is commonly performed via freeze coring, box coring, or multi-coring, yet such coring methods are frequently impractical or unaffordable in remote areas and in developing countries. This study introduces a modular Autonomous Gravity Corer (AGC) with pneumatic core catcher that can be constructed inexpensively, carried to remote locations, and can be deployed from makeshift watercraft. The AGC with adjustable sinking speed proved its utility for recovery of undisturbed laminated sediment from Biển Hồ maar lake in central Vietnam. Maar/crater lakes and dry maars in Vietnam and neighboring countries offer long-time paleoclimatic archives [3,4]. Global warming increases atmospheric humidity and will likely affect the monsoon system and the impact of typhoons in Vietnam and elsewhere (e.g., [5]). Preliminary evidence indicates that Biển Hồ 
maar lake sediment holds a record of monsoon-related erosion from its small volcanic catchment in the form of structurally distinct flood deposits [6].

Recent advances in optical microscopy, Scanning Electron Microscopy (SEM), and Transmission Electron Microscopy (TEM) can only be exploited for unconsolidated sediment if the material can be hardened for viewing in a way that does not introduce textural artifacts. Structural studies of unconsolidated, fine-grained sediments (i.e., mud) typically require replacement of interstitial water with a different fluid that eventually hardens and allows cutting of solidified sediment for optical and other forms of imaging. Water-wet sediment cannot be directly impregnated with paraffin or resin mixtures because water is not miscible with hydrophobic fluids. A water-acetone-epoxy exchange method for fine-grained media was first described by Spurr [7] for preserving microfabrics for SEM imaging. Clark [8] used dehydration and subsequent resin-impregnation of lake sediments to achieve epoxy resin impregnation. This method, sometimes slightly altered, has been used by many researchers to preserve the structure in sediments (e.g., [9-12]; additional references are listed in [13]). Sediment with limited amounts of pore water can be shock-frozen and freeze-dried prior to impregnation with resins [12], but this approach can be difficult for water-rich sediment and will generate salt crystals in the presence of saline pore water. Impregnation methods rely on time-consuming sequential baths of wet sediment in relatively large volumes of flammable solvents like ethanol and acetone for removal of water, followed by sequential baths in expensive impregnation fluids. The overall sequence is not only time-consuming, but also costly in terms of the usage of solvents and reagents. Here we present a streamlined procedure that is applicable to batch processing, can be semi-automated, and minimizes usage and cost of chemicals. We technically improve upon an earlier version of rapid epoxy impregnation [14].

\section{Materials and Methods}

\subsection{Maar Site Description}

A cluster of craters was produced by volcanism in the central Vietnamese Highlands as recently as 200,000 years ago in the Gia Lai Province, Vietnam [15]. A few of those craters still feature maar lakes, such as Biển Hồ Lake $\left(14^{\circ} 03^{\prime} 03.5^{\prime \prime} \mathrm{N}, 108^{\circ} 00^{\prime} 00.2^{\prime \prime} \mathrm{E}\right)$ near the city of Pleiku (Figure 1). With a water depth of up to $\sim 21 \mathrm{~m}$, this environmentally protected natural lake serves as a freshwater reservoir and, with the exception of seasonal inflow over a concrete sill during highstand of an artificial reservoir to the northwest since 1983, features a simple hydrology without inflow or outflow. The catchment is limited to a narrow and steep crater rim exposing exclusively basaltic regolith and its weathering products. The northern section of the maar lake covers an area of $\sim 2.3 \mathrm{~km}^{2}$ with a mostly flat bottom topography under thermally stratified waters for most of the year. The sediment in the deepest part of the maar is laminated anoxic mud. The softness of topmost sediment with $>90 \mathrm{wt}$. \% water can make it challenging to recover an undisturbed sediment/water interface with conventional gravity coring. The maar's low crater rim permits winds to sweep the maar lake, especially above the deepest northern part. Our initial paleolimnologic work required an inexpensive coring method that was able to recover the sediment/water interface despite windy conditions making it difficult to hold a steady coring position on the lake.

\subsection{Autonomous Gravity Corer with Pneumatic Core Catcher}

\subsubsection{Construction and Function}

The AGC is designed to sink autonomously from the water surface to the sediment with adjustable speed while the operator in a watercraft exerts no physical force during the descent (Figure 2A,B). Slight lateral drift of the watercraft due to wind or current does not influence the coring. The lower, cylindrical part of the corer consists of two sections: (1) an upper, translucent core liner (e.g., clear PVC tubing length $117.5 \mathrm{~cm}$ for one section; inner diameter $5.0 \mathrm{~cm}$; part number LNRT325-4 from 
ESP Supply, Irvine, CA, USA); and (2) a reusable pneumatic core catcher that is attached to the upper translucent core section with duct tape and secured with a steel cable. The lower part of the core catcher consists of a $30 \mathrm{~cm}$ section of translucent core liner with two oval, $\sim 10 \mathrm{~cm}$ long and $\sim 5 \mathrm{~cm}$ wide cutouts on opposite sides near the bottom (Figure 2C). The two cutouts are overlain on their outside by two rubber bladders made from $20 \mathrm{~cm}$ sections of bicycle inner tubes that have one end closed and the other end connected to plastic tubing (Figure 2D). External layers of duct tape ensure that inflation of bladders occurs towards the interior. The two pieces of plastic tubing from the two bladders join at a Y-connector (Figure 2E) and from there lead via sufficiently long (e.g., $25 \mathrm{~m}$ ) plastic tubing to a T-valve and a $500 \mathrm{~mL}$ plastic syringe in the watercraft. Metal hose clamps secure the tubing on connectors. Upon inflation of the bladders, when the syringe pump injects water through the plastic tubing, the rubber of the bladders will bulge inward through the oval cutouts and block sediment from exiting the core liner through the core catcher (Figure 2F). It is not recommended to use air pressure for inflating the rubber bladders, because the volume of compressible air needed to close the core catcher at water depths of 10 to $20 \mathrm{~m}$ will expand by factors of ca. 2 to 3 upon return to the water surface, which may cause rupturing of the bladders. Prior to deployment of the corer, any air in bladders, connectors and the plastic hose should be replaced with water.
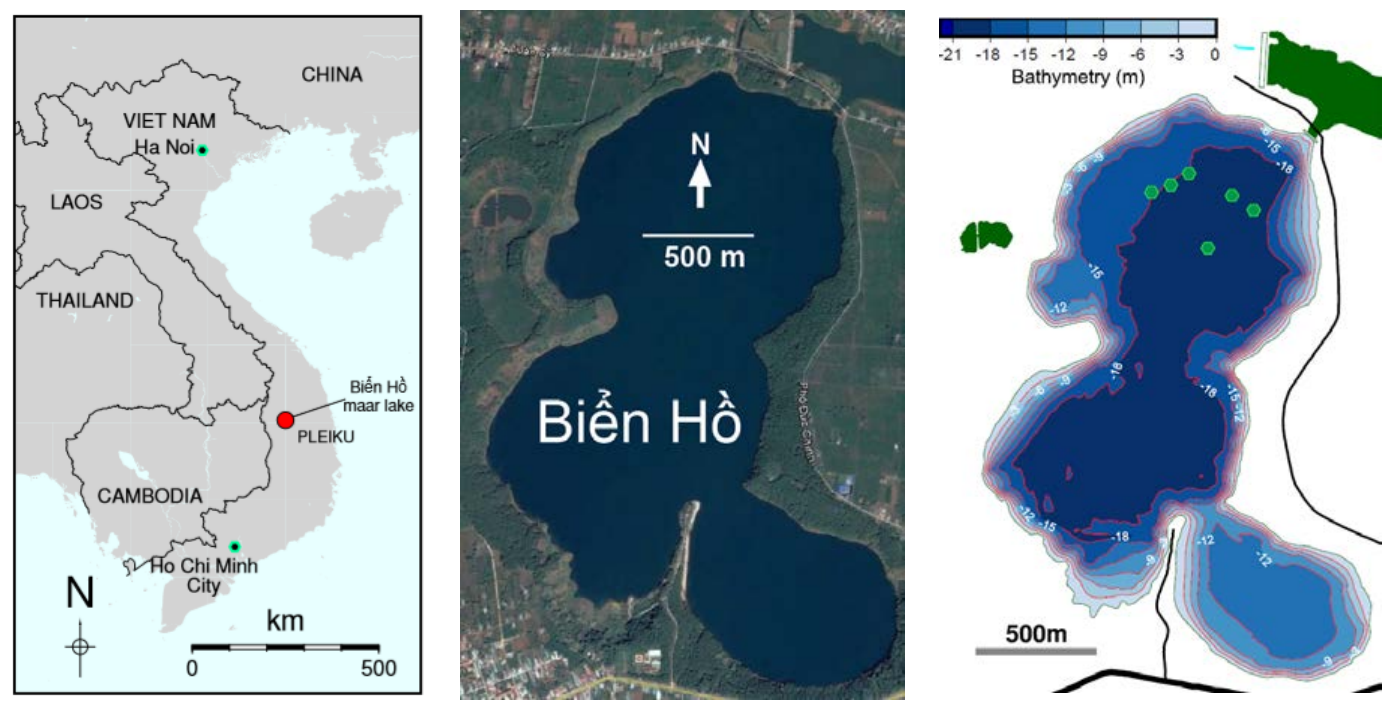

Figure 1. Central Vietnam's Highlands feature a cluster of maars near Pleiku. We cored Biển Hồ maar lake containing modern anoxic, laminated sediment (selected coring sites identified by green hexagons on bathymetric map).

The core liner is attached with duct tape or mechanical fasteners to a $\sim 2 \mathrm{~m}$ long pole of bamboo, wood or metal (Figure 2A). Additional weight to penetrate stiff sediment can be provided by rock ballast (e.g., local rocks in wire or plastic mesh) attached to the lower section of the pole. The upper section of the pole attaches to an upside-down, empty large plastic container with no cap. A small hole in the top of the container connects to a plastic air valve that can be set to slowly bleed air from the container. An inexpensive bleed valve with short tubing is available from disposable intravenous infusion assemblies. Instead of attaching the plastic container directly to the upper end of the pole, it can also be tied upside-down to a $\sim 2 \mathrm{~m}$ long rope that can latch to the upper pole with a quick-release spring clip (e.g., carabiner). Segments of styrofoam can be taped to the upper part of the pole to ensure a vertical position of the AGC in the water column and to adjust the velocity during descent. The balance between the amount of rock ballast and the volume of styrofoam determines the speed of impact (and hence the likelihood of preserving the topmost sediment layer) and the penetration depth. Rope tied to the top of the pole is used for core recovery and runs parallel to, but independently from the plastic hose for pumping water into the rubber bladders. 
Visual information about optical conditions along the water column and the behavior of the surface sediment during coring can be recorded with a waterproof action-style camera that can be mounted to the core liner. The presence of nepheloid-laden bottom waters requires an accessory battery-operated light source to illuminate the sediment surface.

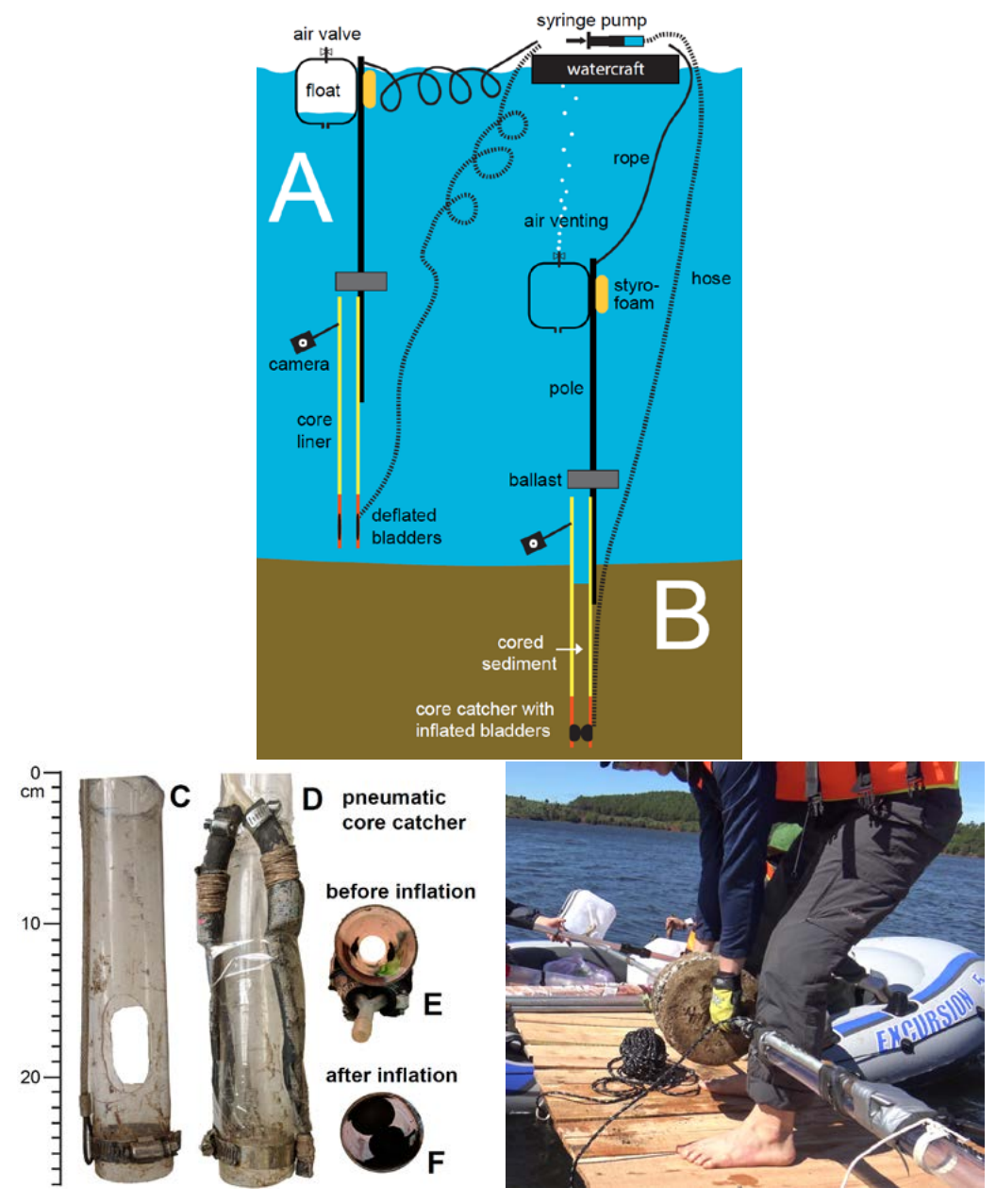

Figure 2. Left: Schematic operation of the Autonomous Gravity Corer (AGC) with pneumatic core catcher. (A) Initially the coring assembly is floating freely and slowly losing buoyancy when air is bleeding out of the air valve above the float. Generous lengths of rope and hose are being paid out during vertical descent, while styrofoam at the top of the assembly maintains a vertical orientation. An underwater camera can be attached to document benthic conditions and coring. (B) After penetration into the sediment, a syringe pump is used to inflate the rubber bladders of the core catcher (i.e., lower red extension of yellow core liner) with water, followed by pulling on the rope to retrieve the AGC. The depicted size of the coring equipment is not commensurate with actual water depth. Bottom left: Main components of the pneumatically operated core catcher $(\mathbf{C})$ before attaching two bladders made from bicycle inner tubes, and (D) with bladders. Core catcher and core liner have the same diameter $(\mathbf{E})$. Inflation of bladders with water $(\mathbf{F})$ closes two thirds of the core catcher's cross section. Core liner and core catcher are connected with duct tape and secured by steel cable attached to hose clamps. Bottom right: J.P.S. lifts the assembled sediment corer in preparation for deployment in 21 m deep Biển Hồ Lake in 2017. Cement disks serve as ballast. Central Vietnam's Highlands feature a cluster of maars near Pleiku. We cored Biển Hồ maar lake containing modern anoxic, laminated sediment (selected coring sites identified by green hexagons on bathymetric map). 


\subsubsection{Deployment}

The AGC can be assembled on land or in shallow water near the shore and floated to the coring position while the air valve is closed. Although the photograph in Figure 2 shows a primitive coring platform between two inflatables, the assembled AGC can also be towed by, and deployed from a single inflatable. In preparation for deployment, both rope and plastic tubing need to be carefully coiled. Once in position, the air bleed is activated, and the corer gradually loses buoyancy. At the onset of the AGC's descent, rope and plastic tubing are being paid out rapidly from the watercraft to avoid any forcing of the AGC. After impact into the sediment, the water-filled syringe is used as a hand-operated pump to fill the rubber bladders with a prescribed volume of water, followed by closure of the T-valve.

\subsubsection{Recovery}

Only the rope must be used to pull the AGC up to the water surface. Verticality must be maintained at all times if the sediment is water-rich and can be easily disturbed by tilting. The large, water-filled plastic container will appear first. The plastic container can be temporarily lifted out of the water and filled with air. After closing the bleed valve, the container again serves as a flotation device while the AGC is tied in vertical position to the side of the watercraft and towed to shore. The alternative design of tying the plastic container with a short rope to the pole allows for convenient detachment without the need for lifting. The sediment core can be recovered from the AGC assembly by (i) removing some of the tape that connects the core catcher to the core liner, (ii) inserting a piece of sheet metal between the core liner and the core catcher, (iii) removing all of the connecting tape and the core catcher while using the sheet metal to secure the sediment in the core liner, and (iv) placing a cap onto the lower end of the core liner while the sheet metal is slowly withdrawn. Instead of performing these tasks in a small watercraft, help should be enlisted to work onshore or on a stable coring platform. Alternatively, the use of multiple pneumatic core catchers during a coring campaign would make it possible to keep core catchers securely attached to core liners, cap the bottom of each core catcher, and transport sediment-filled liners with core catchers back to the laboratory.

After recovery of sediment cores, the topmost sediment can be structurally stabilized by first syphoning off most of the supernatant water from the core liner, and then adding a few grams of Zorbitrol ${ }^{\circledR}$ Plus (Misco Inc., Holmdel, NJ, USA) to form a polyacrylate gel above the sediment $[16,17]$ (p. 98).

\subsection{Rapid Spurr Epoxy Impregnation of Mini-Subcores}

Small volumes of wet, unconsolidated sediment that are enclosed in a porous, non-soluble material can be immersed in solvents and liquid epoxy resin for rapid exchange of pore fluids. Our example below recommends tubes from stainless steel cloth, but other materials like heavy-duty cellulose paper and polymer cloth can be used if they are sufficiently stiff and can be sewn to form stable tubes that can be inserted into wet sediment. Rectangular sections of woven T316 stainless steel 635 mesh (TWP, Berkeley, CA, USA) are cut to size (Figure 3, A) and rolled over a steel rod B (e.g., $8.2 \mathrm{~mm}$. o.d.) to form a tube $C$ with a narrow overlap, then both rod and tube are inserted into a slightly larger metal tube $\mathbf{D}$ (e.g., brass with $9.2 \mathrm{~mm}$ i.d.) for temporary mechanical stabilization of the overlap. Tube $\mathbf{D}$ is gradually withdrawn while the overlapping part of the emerging tube $\mathbf{B}$ is sequentially spot-welded by brief contacts with a graphite rod $\mathbf{E}$ that is electrically charged with a few volt (AC or DC) relative to the steel/brass assembly. After spot-welding, the steel mesh tube $\mathrm{C}$ is withdrawn from the steel rod and protruding steel filaments are trimmed off at both ends of $\mathbf{C}$. Tube $\mathbf{C}$ can be covered with one or more applications of clear nail polish to enhance its stiffness and making it temporarily impermeable. Drying of the nail polish yields a watertight metal tube with sufficient mechanical strength to be tapped into soft sediment. Alternatively, an external metal tube like $\mathbf{D}$ can be used for external support of the stainless steel mesh tube $\mathbf{C}$ when entering sediment, after making short longitudinal incisions 
around one end of $\mathbf{C}$ and bending flaps of steel mesh outwards over the rim of $\mathbf{D}$. Any diameter of $\mathbf{C}$ in excess of $1 \mathrm{~cm}$ makes fast impregnation with Spurr resin impractical.
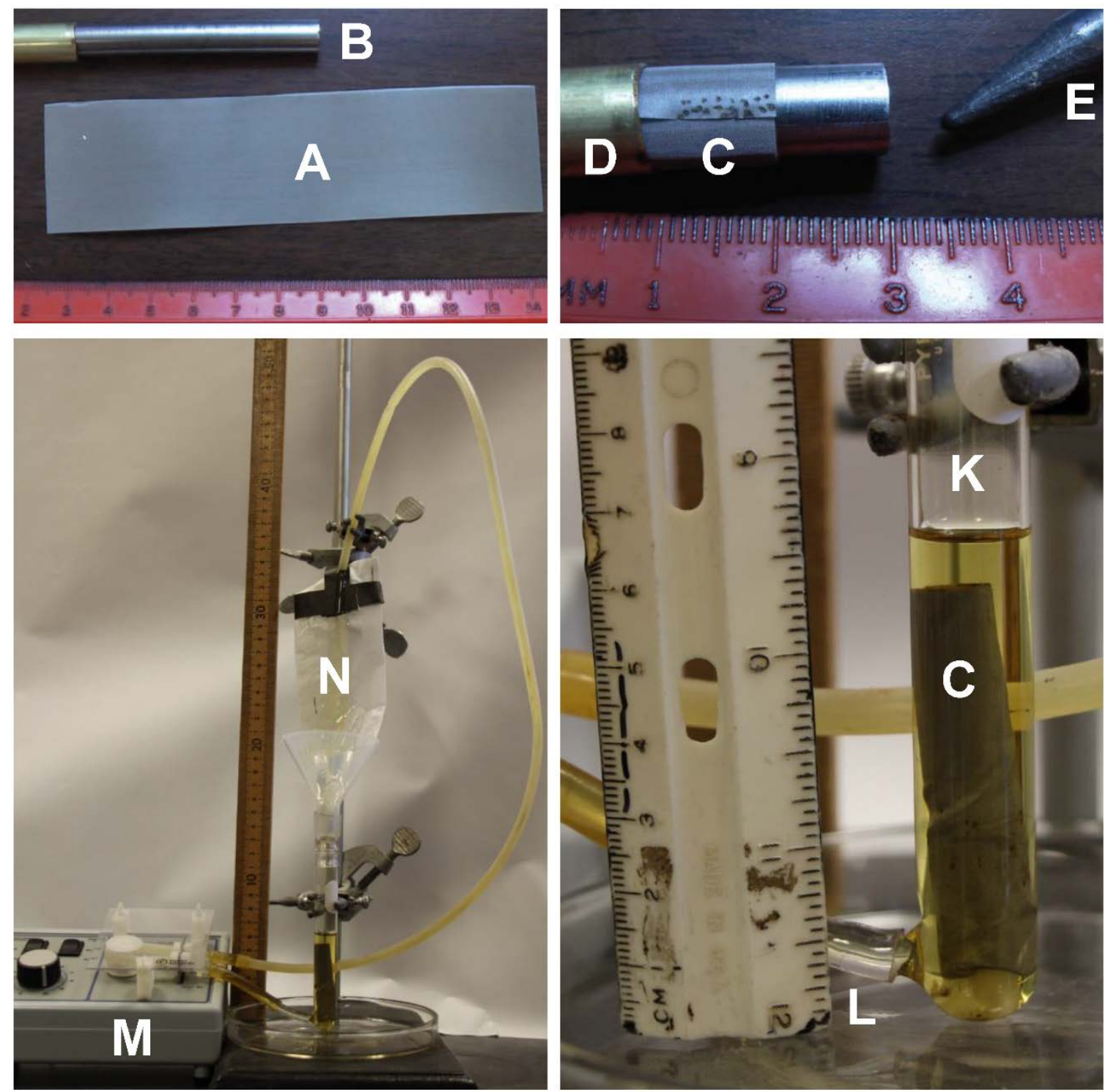

Figure 3. A microporous sheet of woven stainless steel mesh $\mathbf{A}$ is rolled around a steel rod $\mathbf{B}$ inside a brass tube $\mathbf{D}$ to form a mini-core liner $\mathbf{C}$ that is spot-welded with a graphite rod $\mathbf{E}$, optionally stiffened with a coat of clear nail polish, and filled with unconsolidated sediment. Top and bottom of the sediment are secured with cotton plugs. The sub-core is placed vertically into a glass apparatus $\mathbf{K}$ for step-wise (i) dissolution of nail polish with acetone, (ii) exchange of any saline interstitial water with deionized water, then (iii) removal of pore water in acetone, and finally (iv) removal of acetone by epoxy resin. A peristaltic pump $\mathbf{M}$ circulates the resin from the bottom of the glass apparatus through plastic tubing $\mathbf{L}$ onto an exposed strip of filter paper $\mathbf{N}$ above the glass apparatus for rapid evaporative removal of acetone. The devolatilized resin drips back into a funnel and into the glass apparatus. Recirculation of resin is stopped after $\sim 3$ days when the viscosity prevents sufficient flow through the peristaltic pump. This setup greatly limits the needed volume of expensive resin, especially when multiple sediment mini-cores are treated simultaneously in batch mode. Final curing of the resin occurs at $60{ }^{\circ} \mathrm{C}$. See further explanations in the methods section.

After inserting tube $\mathbf{C}$ into the wet sediment, a spatula is inserted into the sediment next to tube C. External sediment is slightly pushed sideways to establish an air channel and to avoid a vacuum at 
the bottom during uplift of tube $\mathbf{C}$. After extraction of the filled tube $\mathbf{C}$, both ends of the tube receive plugs of cotton wool, ideally with colored wool marking top and bottom. Drying and the entering of air into the sub-core need to be avoided. The wet subcore in tube $\mathbf{C}$ is placed into a vertically mounted glass tube $\mathbf{E}$ connecting to a plastic tube $\mathbf{L}$. Technical grade acetone is added into $\mathbf{K}$ and after a few minutes drained through $\mathbf{L}$ by temporarily lowering $\mathbf{L}$, followed by new addition of fresh acetone into K. After a few cycles of rinsing with acetone, the nail polish sealing the pores of the steel mesh will have dissolved and the pore water along the sediment subcore will begin freely exchanging with acetone. At this time, it may be necessary to begin exchanging any saline pore water in sediment with deionized water until the salinity becomes negligible. Typical non-saline lacustrine sediments will directly continue treatment with acetone. Quantitative exchange of pore water with acetone will take a few days and require several exchanges of acetone in $\mathbf{K}$ with new acetone. Two or more subcores can be placed into a larger metal or glass container and receive simultaneous treatment instead of using glass tube $\mathbf{K}$ for a single subcore.

After exchange of pore water with acetone, the sediment must stay submerged in acetone until freshly mixed Spurr resin (Polysciences, Inc., Warrington, PA, USA) is available. The four components of the resin are: (1) ERL 4221; (2) diglycidyl ether of polypropylene glycol (D.E.R. 736); (3) nonenyl succinic anhydride (NSA); and (4) dimethylaminoethanol (DMAE). A suitable mixing ratio is 16.4:5.72:23.6:0.4 by weight. The plastic tube $\mathbf{L}$ is temporarily disconnected from $\mathbf{K}$ and the acetone is drained, followed immediately by re-connecting $\mathbf{L}$ to $\mathbf{K}$ and the intake of a peristaltic pump $\mathbf{M}$ (e.g., Fisherbrand ${ }^{\mathrm{TM}}$ Variable-Flow Peristaltic Pump). Fresh epoxy resin is poured into K. The peristaltic pump circulates the resin through plastic tubing to the top of a large filter paper $\mathbf{N}$ above a funnel that rests on $\mathbf{K}$. Acetone in the epoxy mixture will rapidly evaporate while passing over the filter paper. Devolatilized Spurr resin will drip into the funnel and be guided back into K. During the first two days of recirculation, additional Spurr resin needs to be occasionally dripped into the funnel to compensate for lost acetone and to keep the sediment submerged under resin. The peristaltic pump should be kept running at room temperature for as long as the viscosity of the Spurr resin is low enough to allow flow, i.e., up to 3 days. The pump is eventually turned off and tubing is disconnected when the recirculating resin becomes too viscous. $\mathbf{C}$ is extracted from $\mathbf{K}$ with forceps and placed into an oven for hardening of Spurr resin at $60^{\circ} \mathrm{C}$. The plastic tubing of the peristaltic pump needs to be cleaned immediately with acetone. After 3 or more days of resin hardening in an oven, $\mathbf{C}$ can be cut with a saw in preparation for mounting of a thin section on a glass slide.

\section{Results}

\subsection{Coring}

Repeated field work in Biển Hồ Lake in 2016, 2017 and 2018 offered opportunities to improve the design of the AGC and to optimize the balance between rock ballast and styrofoam according to specific coring objectives, namely to either gently recover the topmost sediment layers, or to maximize the speed of impact for deeper core recovery. Sediment cores from different coring campaigns differed greatly in their appearance of the sediment-water interface. Microbial mats were observed in March 2016 (Figure 4A), November 2017, and March 2018 (Figure 4B). Severe flooding in Central and South-Central Vietnam caused significant damage to infrastructure after September 2016 [18]. The agricultural reservoir to the Northeast of Biển Hồ Lake spilled over and caused erosion of red clay behind a concrete sill where water entered Biển Hồ Lake. Coring in Biển Hồ Lake in January 2017 demonstrated that the eroded red clay, together with minerals washed down from the crater rim, had partially settled as a topmost flocculous reddish layer. Repeat coring in November 2017 showed that the red iron oxides of the 2016 flood layer had been reduced, their red color lost in the anoxic benthic environment, and had been covered with a new microbial mat. A March 2018 core demonstrated the undisturbed laminated structure of most recent sediment (Figure 4C,D). Deeper sediment may have been disturbed by anchor stones that had been dropped by fishermen to secure their nets. 

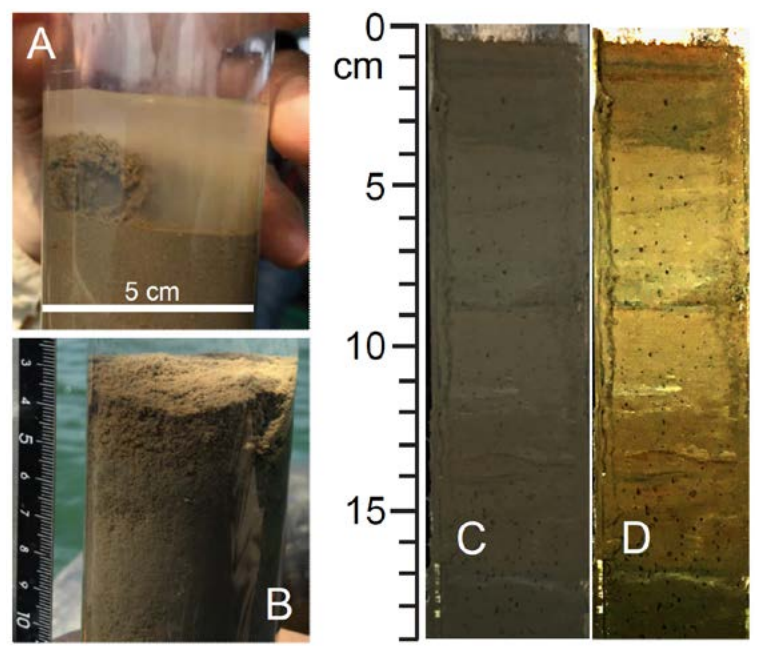

Figure 4. (A) A microbial mat from the previous dry season was curling up in March 2016 after the core was inadvertently tilted during recovery from the water column. (B) Preserved bacterial mat on freshly recovered, undisturbed core in March 2018. (C) Image of the same March 2018 core after splitting of the core and scraping of the surface, one week after coring, and (D) after enhancing the contrast and brightness with Adobe Photoshop.

\subsection{Epoxy Impregnation}

A Biển Hồ sediment core from March 2016 was positioned vertically for dewatering in Pleiku for several months before its transport to Hanoi and to Indiana University. The sediment surface had been slightly oxidized by the time of subcoring with a microporous tube of woven stainless steel mesh at Indiana University in the summer of 2017. The Spurr epoxy-embedded sub-core was cut, polished, and optically scanned. After brightening with Adobe Photoshop, red horizontal banding indicated zonal oxidation near the top, in addition to faint lamination at depth (Figure 5A).
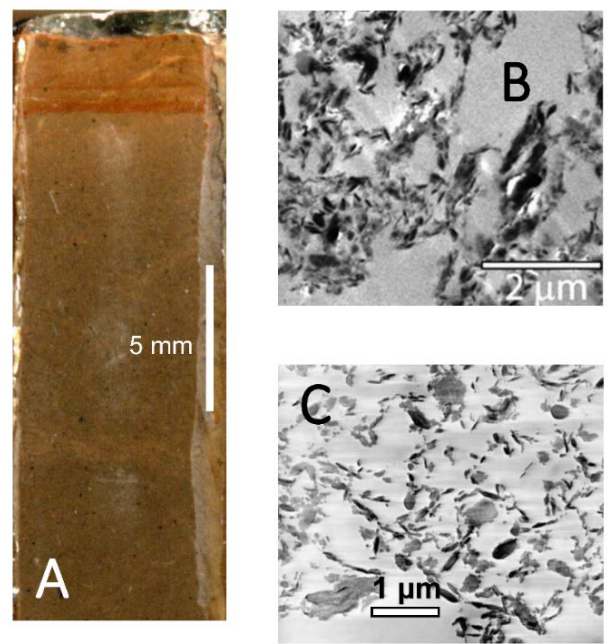

Figure 5. (A) A Spurr epoxy-embedded sub-core from topmost January 2017 Biển Hồ sediment in stainless steel fabric was cut, polished, and optically scanned. The image was brightened with Adobe Photoshop. The red horizontal banding on top is a zonal oxidation artifact resulting from storage in air. A summer 2016 flood deposit accounts for the interval from ca. 5 to $15 \mathrm{~mm}$. (B) A sediment sample from a flume study was epoxy-embedded, thin-sectioned, and imaged with Transmission Electron Microscopy following a traditional procedure that preserves the microstructure of water-rich sediment $[19,20]$. (C) Another aliquot of the same flume sediment was epoxy-impregnated with our new method, thin-sectioned, ion-milled, and imaged with Scanning Electron Microscopy. 
A more detailed evaluation of the ability of our epoxy impregnation method to preserve the microstructure of water-rich, unconsolidated sediment relied on laminated artificial sediment from a flume study [21]. The flume sediment with 85 to 95 volume \% water and up to 4 dry weight $\%$ organic carbon was comparable to modern Biển Hồ sediment. The flume sediment was 'cored' with a large plastic straw, fixated in glutaraldehyde, dried at the critical point of carbon dioxide, and resin-impregnated in a traditional resin bath according to procedures that are known to preserve the microstructure $[19,20]$. A thin-section was prepared and stained with osmium and uranium to enhance contrast, followed by imaging with Transmission Electron Microscopy to visualize the distribution of grains in sediment (Figure 5B). For comparison, a mini-core of the same water-wet sediment in a stainless steel mesh tube underwent our epoxy-impregnation procedure, thin-sectioning, argon ion-milling, and imaging by Scanning Electron Microscopy (Figure 5C). The similar distribution and association of particles in both samples at the $\mu \mathrm{m}$-scale testifies to the preservation of the sedimentary microstructure during epoxy-embedding.

\section{Discussion}

\subsection{Autonomous Gravity Corer}

Commercially available gravity coring equipment is typically not readily available in many developing countries. Furthermore, its weight hampers deployment in remote regions. Most gravity corers are using weight and speed for darting fast into sediment $[16,22,23]$, which can complicate adequate recovery and preservation of topmost softer sediment. Our technical solution for gravity coring with adjustable speed can be implemented inexpensively with simple materials and tools. Its modular design facilitates transport and storage. Our AGC sinks vertically through the water column and cannot be affected by winds or slight movement of the watercraft as long as the position of the watercraft relative to the ground is kept stable enough to avoid tilting of the AGC in the sediment immediately after coring and during extraction from the sediment. The sediment/water interface is cored best if the descending gravity corer contacts the sediment at zero lateral ground speed, which is typical for most lakes with limited movement of bottom water. In contrast, coastal marine, deltaic and river environments may have bottom water moving swiftly over the sediment. In such situations, a geostationary corer deployed from an anchored platform and guided by a rigid coring assembly may be better suited to recover the sediment/water interface.

Pneumatic core catchers with inflatable rubber elements are available commercially and provide reliable service, for example as part of the Beeker-sampler from Unoson Environment AB (Mölnlycke, Sweden [24]). The Beeker sampler's core catcher is designed for complete closure, which is not required for most sediments with adequate cohesion at a depth of a few decimeters. Apart from being affordable, a simpler design as described in this paper can be easily repaired and replaced locally using resources that are universally available (e.g., old inner tubes, rubber cement, duct tape).

Preservation of the sediment/water interface during coring also requires that the water in the empty core liner is freely moving upward during the descent of the core liner. Stagnant water in the core liner would act as a hammer when the gravity corer impacts the sediment. The design of the core catcher features no protruding elements impeding the interior water flow prior to contact with sediment. We found it unnecessary to attach a lid on top of the core liner to provide 'suction' when retrieving the AGC.

The described method of affordable gravity coring is useful for water depths up to a few tens of meters only, because greater depth would exacerbate the danger of tangling of rope and plastic hose during descent and retrieval. Pulling of a tangled rope for core recovery could also pull the plastic hose off its connection to the pneumatic core catcher and result in sediment loss. The achievable coring depth in sediment depends on the net weight of the coring assembly in water, the diameter of the core catcher and core liner, the hydrodynamic properties of the coring assembly (i.e., drag), and the physical properties of the sediment. Adding more ballast increases the speed of sinking and the 
depth of sediment recovery but decreases the likelihood of recovering an undisturbed sediment/water interface. A suitable balance between ballast near the bottom of the pole and Styrofoam at the top of the pole ensures vertical positioning of the AGC and adjusts the speed of sinking towards specific coring objectives.

\subsection{Epoxy-Impregnation}

In addition to Spurr-type epoxy resin, a variety of other hydrophobic embedding media can be used in the described technique after slight adjustments in terms of times and temperatures. For example, hydrocarbon waxes, crystic resin [25], polyester resin (Polylite ${ }^{\circledR} 32032-00$ ), and Araldite MY750 epoxy resin with hardener HY956 have found use for impregnation of sediments. PaleoBOND (CO Division, Woodland Park, CO, USA) reacts fast with moisture in sediment and air and would not be suitable for the refluxing technique described in this study. Workers are advised to handle all organic solvents and uncured resins in fume hoods or in well-ventilated environments and to avoid inhalation and skin contact. Acetone is flammable. Uncured resins may contain toxic substances.

\section{Conclusions}

An affordable and lightweight Autonomous Gravity Corer with pneumatic core catcher has been developed and tested for recovery of short sediment cores from water depths up to $21 \mathrm{~m}$, with potential for deeper coring. Autonomous descent through the water column at controlled speed can preserve the sediment/water interface. The corer can be deployed from small makeshift watercraft without the need for an anchored platform. The modular design from low-cost and globally available materials, as well as the portability of the corer for deployment in remote areas make this corer especially useful in developing countries.

An economical and fast water-acetone-epoxy-exchange method is presented for resin-impregnation in preparation for imaging of sedimentary structures in fine-grained unconsolidated sediment. The method is useful for documenting small-scale textural features that are difficult to preserve in sediment, such as lamination and bioturbation features, which are critical for facies analysis in fine-grained units. Advantages are (1) reduced use of solvents and reagents, (2) increased speed of epoxy resin impregnation, and (3) minimal disruption of sedimentary structures.

Author Contributions: J.S. and A.S. conceived and designed the equipment; J.S. operated the AGC during two campaigns; H.N.-V. and D.N.-T. planned the logistics of all field work and operated the AGC in March 2018; all authors jointly wrote the manuscript and prepared Figures; J.S. and A.S. revised the manuscript.

Acknowledgments: The early phase of development of rapid epoxy resin impregnation had been supported by U.S. National Science Foundation Marine Geology and Geophysics grant \#0930829 “Collaborative Research ETBC: Combined experimental and theoretical study of the physical mechanisms underlying deposition, degradation and preservation of marine organic carbon" to A.S. Our manuscript benefited from H.N.'s NSF-supported training at the LacCore/CSDCO Drilling and Coring Summer Institute at the University of Minnesota in 2017. We are indebted to Thân Tạ-Văn from the Gia Lai Department of Natural Resources and Environment, Đỗ Văn Thạch, Đỗ Ngọc Điệp, Nguyễn Ánh Nguyệt and Đỗ Trọng Quốc for administrative, logistic, and practical support during coring. Juergen Schieber made available SEM and TEM images. Ingmar Unkel provided duct tape, practical advice and humor towards technical improvement of the AGC. The constructive feedback from two expert reviewers improved the manuscript.

Conflicts of Interest: The authors declare no conflict of interest. The founding sponsors had no role in the design of the study; in the collection, analyses, or interpretation of data; in the writing of the manuscript, and in the decision to publish the results.

\section{References}

1. Zolitschka, B.; Francus, P.; Ojala, A.E.K.; Schimmelmann, A. Varves in lake sediments-A review. Quat. Sci. Rev. 2015, 117, 1-41. [CrossRef]

2. Schimmelmann, A.; Lange, C.B.; Schieber, J.; Francus, P.; Ojala, A.E.K.; Zolitschka, B. Varves in marine sediments: A review. Earth Sci. Rev. 2016, 159, 215-246. [CrossRef] 
3. Sun, Q.; Shan, Y.; Sein, K.; Su, Y.; Zhu, Q.; Wang, L.; Sun, J.; Gu, Z.; Chu, G. A 530 year long record of the Indian Summer Monsoon from carbonate varves in Maar Lake Twintaung, Myanmar. J. Geophys. Res. 2016, 121, 5620-5630. [CrossRef]

4. Yang, Y.; Zhang, H.; Chang, F.; Meng, H.; Pan, A.; Zheng, Z.; Xiang, R. Vegetation and climate history inferred from a Qinghai Crater Lake pollen record from Tengchong, southwestern China. Palaeogeogr. Palaeoclimatol. Palaeoecol. 2016, 461, 1-11. [CrossRef]

5. Yang, S.; Ding, Z.; Li, Y.; Wang, X.; Jiang, W.; Huang, X. Global temperature change as the ultimate driver of the shift in the summer monsoon rain belt in East Asia. Proc. Natl. Acad. Sci. USA 2016, 113, E2211-E2212. [CrossRef] [PubMed]

6. Nguyễn-Văn, H.; Nguyễn-Thùy, D.; Schimmelmann, J.P.; Zolitschka, B.; Tạ-Văn, T.; Nguyễn-Ánh, N.; Tạ Hòa, P.; Đặng-Phương, T.; Lê-Quyết, T.; Nhi Phạm-Nữ, Q.; et al. Exploring the Paleoenvironmental Potential of Laminated Maar Sediment in Central Vietnam: An Archive of Regional Paleo-Flooding? In Proceedings of the PAGES 5th Open Science Meeting, Zaragoza, Spain, 9-13 May 2017; p. 325.

7. Spurr, A.R. A low-viscosity epoxy resin embedding medium for electron microscopy. J. Ultrastruct. Res. 1969, 26,31-43. [CrossRef]

8. Clark, J.S. Stratigraphic charcoal analysis on petrographic thin sections: Application to fire history in northwestern Minnesota. Quat. Res. 1988, 30, 81-91. [CrossRef]

9. Boës, X.; Fagel, N. Impregnation method for detecting annual laminations in sediment cores: An overview. Sediment. Geol. 2005, 179, 185-194. [CrossRef]

10. Smith, S.J.; Anderson, R.S. A method for impregnating soft sediment cores for thin-section microscopy. J. Sediment. Res. 1995, 65, 576-577. [CrossRef]

11. Card, V.M. Varve-counting by the annual pattern of diatoms accumulated in the sediment of Big Watab Lake, Minnesota, AD 1837-1990. Boreas 1997, 26, 103-112. [CrossRef]

12. Lotter, A.F.; Lemcke, G. Methods for preparing and counting biochemical varves. Boreas 1999, $28,243-252$. [CrossRef]

13. Schimmelmann, A. Varve-Related Master Reference List Compiled for the PAGES Varve Working Group (VWG) Containing >1750 References. 2018. Available online: http://pastglobalchanges.org/download/ docs/working_groups/vwg/2018-varves-publicns-feb.pdf (accessed on 1 May 2018).

14. Schimmelmann, A.; Riese, D.J.; Schieber, J. Fast and Economical Sampling and Resin-Embedding Technique for Small Cores of Unconsolidated, Fine-Grained Sediment. In Proceedings of the 2015 Pacific Climate (PACLIM) Workshop, Asilomar Conference Grounds, Pacific Grove, CA, USA, 8-11 March 2015.

15. Nguyễn, H.; Flower, M.F.J.; Cung, T.C.; Phạm, T.X.; Hoàng, V.Q.; Trần, T.S. Collision-induced basalt ruptions at Pleiku and Buôn Mê Thuột, south-central Viet Nam. J. Geodyn. 2013, 69, 65-83. [CrossRef]

16. Glew, J.R.; Smol, J.P.; Last, W.M. Sediment core collection and extrusion. In Tracking Environmental Change Using Lake Sediments, Volume 1: Basin Analysis, Coring, and Chronological Techniques; Last, W.M., Smol, J.P., Eds.; Kluwer Academic Publishers: Dordrecht, The Netherlands, 2002; pp. 73-106.

17. Tomkins, J.D.; Antoniades, D.; Lamoureux, S.F.; Vincent, W.F. A simple and effective method for preserving the sediment-water interface of sediment cores during transport. J. Paleolimnol. 2008, 40, 577-582. [CrossRef]

18. United Nations, Viet Nam Office. Details for Viet Nam: Floods Central Viet Nam-Office of the Resident Coordinator Situation Report No. 1. 2016. Available online: http://un.org.vn/en/publications/doc_details/ 533-viet-nam-floods-central-viet-nam-office-of-theresident-coordinator-situation-report-no-1.html (accessed on 1 May 2018).

19. Baerwald, R.J.; Burkett, P.J.; Bennett, R.H. Techniques for the preparation of submarine sediments for electron microscopy. In Microstructure of Fine-Grained Sediments: From Mud to Shale; Bennett, R.H., Bryant, W.R., Hulbert, M.H., Eds.; Springer: Berlin, Germany, 1991; pp. 309-320. [CrossRef]

20. Curry, K.J.; Bennett, R.H.; Mayer, L.M.; Curry, A.; Abril, M.; Biesiot, P.M.; Hulbert, M.H. Direct visualization of clay microfabric signatures driving organic matter preservation in fine-grained sediment. Geochim. Cosmochim. Acta 2007, 71, 1709-1720. [CrossRef]

21. Schieber, J.; Southard, J.B.; Kissling, P.; Rossman, B.; Ginsburg, R. Experimental deposition of carbonate mud from moving suspensions: Importance of flocculation and implications for modern and ancient carbonate mud deposition. J. Sediment. Res. 2013, 83, 1025-1031. [CrossRef] 
22. Frews, C. Coring methods. In Geomorphological Techniques; Ch. 4.1.1; British Society for Geomorphology, 2014; Available online: http://geomorphology.org.uk/sites/default/files/geom_tech_chapters/4.1.1_Coring.pdf (accessed on 1 May 2018).

23. LacCore, National Lacustrine Core Facility, University of Minnesota. Coring Devices. Available online: http:/ /lrc.geo.umn.edu/laccore/devices.html (accessed on 1 May 2018).

24. Unoson Environment AB, Beeker-Sampler, Mölnlycke, Sweden. Available online: https:/ /www.unoson.se/ produkt/beeker-sampler/ (accessed on 1 May 2018).

25. Belbin, S.P. A new standard method of impregnation using crystic resin. J. Sediment. Res. 1994, 64, 673. [CrossRef]

C 2018 by the authors. Licensee MDPI, Basel, Switzerland. This article is an open access article distributed under the terms and conditions of the Creative Commons Attribution (CC BY) license (http:/ / creativecommons.org/licenses/by/4.0/). 